\title{
Los descansos activos y la mejora de los aprendizajes en educación infantil: una propuesta de intervención
}

\section{Active breaks and improvemnt of learnings in preschool: a proposal of intervention}

\author{
Juan Carlos Pastor-Vicedo ${ }^{1}$, Jesús Martínez-Martínez ${ }^{1}$, Yolanda Jaén Tévar ${ }^{1}$ y Alejandro Prieto-Ayuso ${ }^{1,2, *}$ \\ ${ }^{1}$ Universidad de Castilla-La Mancha. Facultad de Educación (España). \\ ${ }^{2}$ Albacete Balompié S.A.D. (España).
}

Resumen. El objetivo de este trabajo es el estudio de la relación entre los descansos activos y el rendimiento académico en nińos del segundo ciclo de educación infantil, mejorando los diversos contenidos curriculares, a través de juegos de Educación Física. La muestra estuvo compuesta por un total de 50 alumnos, divididos en grupo control $(\mathrm{n}=25)$ y un grupo experimental $(\mathrm{n}=25)$. Para la recopilación de datos se llevaron a cabo dos evaluaciones, una antes de la realización de los descansos activos, pre-test y otra posterior, post-test. Para el análisis de datos se utilizó la prueba t-Student, para medias de muestras relacionadas. Los resultados obtenidos reflejaron la importancia de la actividad física en el rendimiento académico, así como los beneficios transversales que aporta a la salud.

Palabras clave: descansos activos, rendimiento académico, salud y educación infantil.
Abstract. The objective of this work is the study of the relationship between active breaks and academic performance in children preschool education, improving the curricular contents, through physical education games. The sample was formed by 50 participants, divided into a control group $(\mathrm{n}=$ $25)$ and an experimental group $(n=25)$. For the data collection, two evaluations were conducted, one before the programme (pre) and the other one after the programme (post). For the data analysis the t-Student test was used. The results obtained reflected the importance of physical activity in academic performance, as well as the transversal benefits it brings to health. Keywords: active breaks, academic performance, health and child education.

\section{Introducción}

La mayor parte de los colegios de Educación Infantil y Educación Primaria (CEIP) dedican un tiempo insuficiente a la práctica de actividad física estructurada, por lo que los descansos activos adquieren una gran importancia durante la escolaridad obligatoria (Kahn et al., 2002). El Real Decreto 126/2014, por el que se establece el currículo básico de la Educación Primaria, concede mayor autonomía a las Administraciones educativas en relación a la configuración curricular respecto a las asignaturas específicas y de libre configuración autonómica. A estos efectos el Decreto 54/2014, por el que se configura el currículo de Educación Primaria (EP) en la Comunidad de Castilla- La Mancha, establece en su Artículo 8 el horario y calendario escolar, correspondiendo a la Educación Física 2 horas y media al primer ciclo de Educación Primaria y 2 horas al segundo ciclo. En el caso de la Educación Infantil (EI) se contempla en el anexo III, apartado 2.3 de métodos de trabajo del Decreto 67/2007 de currículo, el carácter global de la programación y la unidad del proceso de enseñanza y aprendizaje, no excluyendo la co-

Dirección para correspondencia [Correspondence address]: Alejandro Prieto Ayuso. Universidad de Castilla-La Mancha. Facultad de Educación. Edificio Fray Luis de León. Campus Universitario s/n. C.P. 16071. Cuenca (Espańa). E-mail: Alejandro.Prieto@uclm.es laboración de otros profesionales con la tutoría, tal y como sucede con el área de inglés, religión o con el profesorado de apoyo, de tal modo que adquieren especial relevancia la colaboración el profesorado de Educación Física para estimular, desde la práctica de psicomotricidad, el control del cuerpo, el desarrollo de las habilidades sensomotrices y perceptiva y la expresión gestual y corporal, insistiendo tal normativa a que esta colaboración, en ningún caso, se ha concebir como una práctica aislada, específica y ajena a la propuesta pedagógica de !a tutora o el tutor, aunque si bien es cierto que queda relegado a un segundo plano o a la decisión de la propia administración educativa, ya que no existe ninguna normativa vigente que recurra al mínimo de horas establecidas para tal fin. Sin embargo, García (2013) revela en su estudio que el $53 \%$ del profesorado de EI dedica 1 hora, el 29\% dedica 2 horas y únicamente el 18\% restante dedica más de 2 horas.

Cada vez son más los programas de descansos activos dedicados a la promoción de la actividad física en escolares. En el año 1999 nace el proyecto Take10! creado por la Fundación International Life Sciences Institute, para promover la actividad física, una mejora en la alimentación y el aprendizaje de forma divertida y creativa. Este programa cuenta con la participación de profesionales de la salud y expertos en educación. La filosofía del programa consiste en combinar realida- 
des académicas con diez minutos de actividad física, situadas en los descansos. De esta manera se refuerzan conocimientos de matemáticas, lengua, ciencias sociales o lectura, y se promueve un estilo de vida activo. Este programa permite que el profesor adapte los principios del mismo a las necesidades de sus alumnos.

En el año 2002 empezó a difundirse y desde agosto de 2010, se encuentra implantada en más de 40.000 aulas de educación primaria de EEUU, y expedida a países como son China (Happy10), Reino Unido (Take10 UK), Brasil (Tire10) o Chile (Take10-Chile!) entre otros.

El Ministerio de Sanidad, Servicios Sociales e Igualdad y el Ministerio de Educación, Cultura y Deportes desde el Centro Nacional de Innovación e Investigación Educativa (CNIIE) propuso el programa ;Dame 10! (Descansos Activos Mediante Ejercicio Físico), que son recursos curriculares que se realizan en el marco de la Estrategia de Promoción de la Salud y Prevención (EPSP), en el Sistema Nacional de Salud, $\mathrm{y}$ forman parte de una de las acciones seleccionadas a realizar en el entorno educativo, a fin de mejorar la actividad física que realiza esta población para así promocionar su salud.

Este programa consiste en una batería de actividades que el profesor lleva a cabo cuando estima necesario a lo largo del horario lectivo, en función de los contenidos impartidos en clase. Posee una duración entre 5 y 10 minutos y pretende trabajar los diferentes contenidos curriculares de forma lúdica. Es un programa que tiene como objetivos tanto la mejora de la actividad física como la mejora del rendimiento escolar.

Desde Junta de Comunidades de Castilla-La Mancha en colaboración con la Universidad de Castilla-La Mancha, se ha puesto en marcha el documento Proyectos Escolares Saludables. Descansos Activos, en el que se propone integrar la actividad física dentro del currículo, por medio de breves periodos de tiempo dentro del aula, cuando el docente estime necesario en su grupo clase. Los objetivos principales del programa, que se recogen en la presentación documento son:

- Reutilizar los materiales del programa Take10-Chile! al contexto y currículum educativo de Educación Infantil y Primaria de Castilla-La Mancha

- Probar la aceptación y viabilidad de la metodología basada en la actividad física (AF) integrada en el currículum por parte de los maestros y centros escolares.

- Elaborar un documento que contenga la metodología y algunos ejemplos de los materiales adaptados para que los centros educativos puedan utilizarlo.

La metodología de los descansos activos posee numerosos efectos positivos en términos de salud y de rendimiento académico, como son combatir el sedentarismo, mejorar la forma física de los alumnos, contribuye a paliar las conductas disruptivas, aumentado la motivación y la función cognitiva (Proyectos Escolares Saludables. Descansos activos, 2017).
Por tanto, estos programas ayudan a cumplir las recomendaciones mundiales sobre AF para la salud, según la Organización Mundial de la Salud (2010). Además, este tipo de programas mejoran la disminución de factores de riesgo como puede ser la obesidad, o enfermedades a nivel psicológico y social (Kibbe, Hackett, Hurley, McFarland, Schubert y Schultz, 2011).

Los programas implantados de descansos activos tienen como objetivo primordial trabajar la obesidad y las conductas sedentarias de los alumnos, por medio de AF estructurada en las aulas. En EEUU, con el programa Take10!, más del $40 \%$ de los profesores de educación primaria implantaron esta metodología en tres o más sesiones a lo largo de la mañana, y se comprobaron sus efectos en las quemas de calorías durante los diez minutos de actividad, las cuales rondaron las $24-43 \mathrm{Kcal}$, en función de la intensidad del esfuerzo, de tal forma que, se prevé que el tiempo invertido puede ayudar a la deceleración gradual de la prevalencia del sobrepeso en la población infantil (Kibbe et al., 2011).

Actualmente, investigaciones acerca de la promoción de un estilo de vida activo en los jóvenes (Martinez, Aznar y Contreras, 2015; Herrador-Colmenero, Pérez-García, Ruiz y Chillón, 2014; Sallis, Carlson y Mignano, 2012 destacan estrategias llamativas como los transportes activos al centro escolar, recreos activos, aumento de AF en las horas de tiempo libre o tareas cotidianas que favorezcan la AF evitando sedentarismo (Molina y Martínez, 2014).

Por tanto, en virtud de lo expuesto hasta el momento, el objetivo del presente trabajo fue mejorar y afianzar los contenidos curriculares a través de un programa de descansos activos.

\section{Material y método}

\section{Participantes}

La muestra estuvo formada por un total de 50 alumnos de EI, pertenecientes a dos clases de 3 años. Se utilizó un diseño cuasiexperimental con medidas pre y post, cuya elección de la muestra se realizó por facilidad de acceso al centro educativo. El grupo experimental (GE) estuvo formado por un total de 25 alumnos (13 niñas y 12 niños), y el grupo control (GC) estuvo formado por 25 alumnos (13 niños y 12 niñas). Ninguno de los participantes presentó signos de necesidades específicas de apoyo educativo. Tanto padres, como madres, así como el propio centro fueron informados de los objetivos del estudio. Se obtuvo los respectivos consentimientos informados. El estudio siguió las recomendaciones éticas para el estudio con seres humanos, como así sugiere la Declaración de Helsinki.

Los descansos activos y la mejora de los aprendizajes en educación infantil: una... SPORT TK, 8(2) (supl. 1), 67-72 


\section{Instrumentos}

Se hizo uso de tres instrumentos con la intención de medir el rendimiento académico de los niños, según su edad y los contenidos propios de su etapa educativa.

1. Criterios de evaluación Editorial Edelvives (evaluación inicial). Con el propósito de comprobar si el alumnado posee o no los aprendizajes que se van a trabajar.

2. Batería fotográfica de elaboración propia, inspirada en el test de vocabulario en imágenes Peabody de Dunn, Dunn y Arribas (1997). Esta batería consta de 192 láminas, con cuatro dibujos cada una. El examinador indica al sujeto la ilustración que debe señalar, con la finalidad de evaluar el nivel de vocabulario y la detección de dificultades en la aptitud verbal.

3. Test creado ad-hoc para valorar el rendimiento académico, que consta de nueve diapositivas. Estas diapositivas fueron creadas como soporte a los estándares de aprendizaje, y presentaron información en relación a las vocales (mayúsculas y minúsculas), números (del uno al seis), colores (brown, pink, yellow, green, orange and purple), formas geométricas (círculos, cuadrado, triangulo, pentágono, rombo y rectángulo) y cuatro diapositivas asociadas a conceptos espaciales (arribaabajo, dentro-fuera, grande-pequeńo y largo-corto).

\section{Procedimiento}

En primer lugar, se informó al centro educativo de los objetivos del estudio y la autorización para realizar el trabajo. El siguiente paso fue entregar las oportunas autorizaciones y consentimientos informados a los padres de los alumnos. Junto a ello se planificó la estructura y los contenidos que iban a tener los descansos activos, tomando como base los contenidos curriculares que se estaban tratando en ese momento. Todos los contenidos fueron consensuados con el tutor del grupo clase para que la realización de los descansos activos ayude a los alumnos a mejorar en los diferentes contenidos curriculares seleccionados, afianzando aquellos que ya conocen y con el fin de conocer los que no han sido trabajados.

El periodo elegido para la implantación de los descansos activos se desarrolló desde el 19 de febrero hasta el 13 de abril, con una duración de cinco semanas. Durante los días 15 y 16 de febrero se pasaron las pruebas de evaluación inicial, donde se constata el nivel de partida del alumnado. El día 19 de febrero se presentó el programa al alumnado, informándoles que iba a realizar un estudio para la Universidad de CastillaLa Mancha.

Los lunes, miércoles y viernes a primera hora de la mañana el grupo tenía psicomotricidad, por lo que no se realizó ningún descanso activo antes del recreo, después de este, entre la explicación de dos de las actividades a realizar se desarrolla un descanso activo. Los martes y jueves se hacía un descanso activo a las diez de la mańana, y a la vuelta del recreo cuando termina la clase de inglés se hace otro descanso activo.

El programa se ha desarrollado a lo largo de treinta y cinco sesiones, las cuales se aplican los cinco días de la semana, alternando martes y jueves dos sesiones y el resto de los días solo una. Cada descanso activo duraba alrededor de 15 minutos, dependiendo de las necesidades que el aula posea en ese mismo momento.

Tras el desarrollo de todas las sesiones los días 16 y 17 de abril, se volvieron a pasar las pruebas de evaluación a ambos grupos, por un lado, al grupo experimental con el que se habían trabajado las treinta y cinco sesiones y al grupo control, el cual no ha recibido ningún tipo de estimulación externa, únicamente sus clases ordinarias.

Para la recogida de datos se entrevistó a cada uno de los participantes individualmente, con las respuestas de SI/NO, para completar la tabla de evaluación. Durante la realización de la recogida de datos el alumnado no estaba informado de las actividades que se iban a realizar posteriormente.

\section{Análisis de los datos}

Se hizo uso de un análisis descriptivo para conocer la media y desviación típica. Con el fin de poder establecer posibles inferencias se realizó la prueba T-Student para muestras pareadas. El programa Excel (Versión 16.25, Microsoft) fue usado para el análisis de los datos. Se ha asumido un nivel de significación $p<.05$.

\section{Resultados}

En primer lugar, según los valores totales obtenidos en las pruebas pre y post en relación a la variable colores, los datos obtenidos en las primeras pruebas son similares entre sí. Tras la realización del proyecto se muestra una mejora en ambos grupos, pero los resultados del grupo experimental, donde han sido trabajados los descansos activos, son mejores que los que muestra el grupo control (Figura 1). 


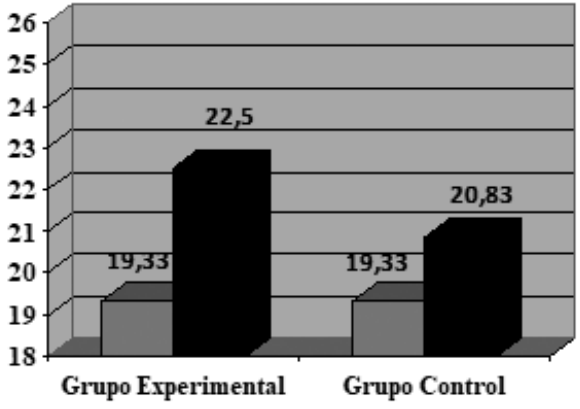

Figura 1. Media del grupo control y grupo experimental en el pre y post en la variable colores.

Posteriormente, tras aplicar el estadístico T-Student se comprobó que las diferencias fueron significativas entre el grupo control y experimental en la medición post $(p=.019)$.

En la figura 2, se observan que los resultados de las pruebas pre y post en la variable conceptos son iguales en ambos grupos. El análisis inferencial reveló que no existieron diferencias significativas $(p=.071)$.
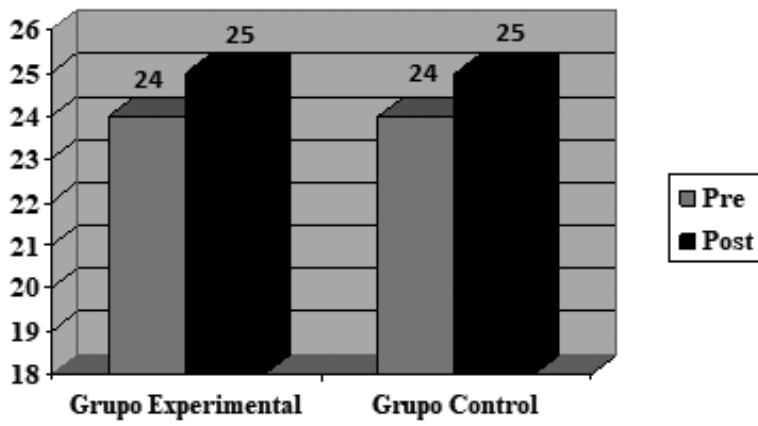

Figura 2. Media del grupo control y grupo experimental en el pre y post en la variable conceptos.

En cuanto a las formas geométricas, la figura 3 muestra las diferencias pre y post en el grupo control y experimental.

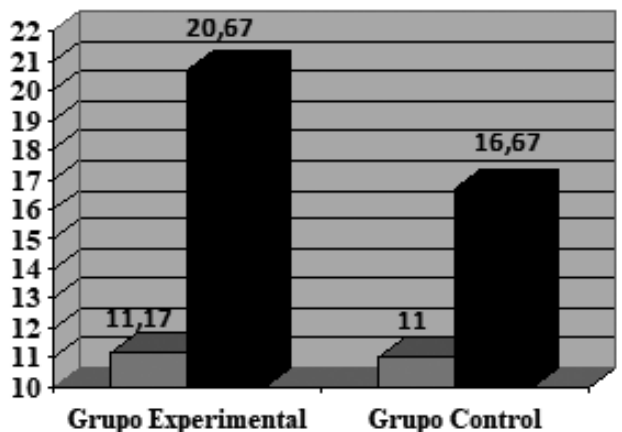

Figura 3. Media del grupo control y grupo experimental en el pre y post en la variable formas geométricas.
De igual forma que en la anterior variable, en este caso las diferencias entre ambos grupos no mostraron diferencias estadísticamente significativas $(p>0.5)$.

En referencia a la variable de números, la figura 4 muestra los resultados pre y post entre el grupo control y experimental. $\mathrm{El}$ análisis inferencial mostró que las diferencias entre ambos grupos fueron no significativas $(p>0.5)$.

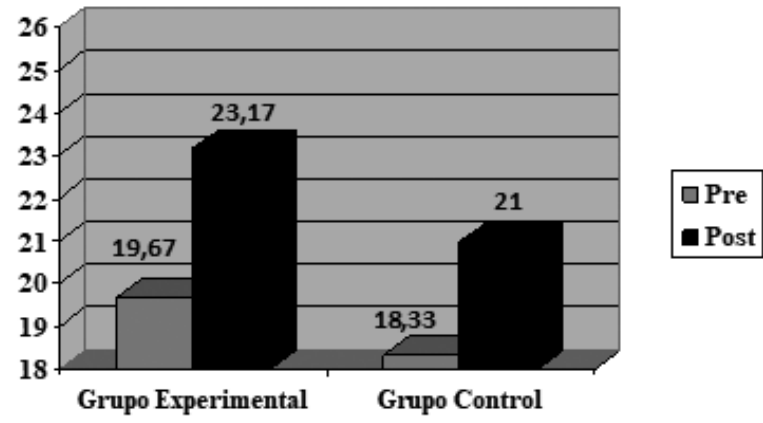

Figura 4. Media del grupo control y grupo experimental en el pre y post en la variable números.

Por último, en cuanto a la variable vocales, la figura 5 muestra los resultados obtenidos entre ambos grupos. En este caso, los resultados inferenciales sí mostraron diferencias estadísticamente significativas en las mediciones post entre el grupo control y experimental $(p=0.3)$.

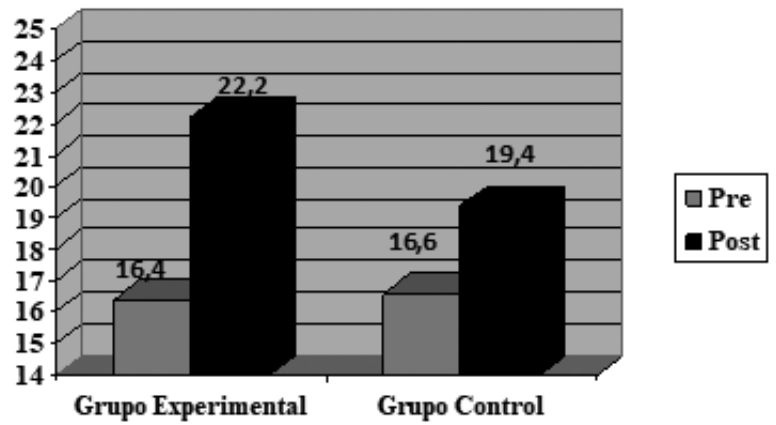

Figura 5. Media del grupo control y grupo experimental en el pre y post en la variable vocales.

\section{Discusión}

El objetivo de esta investigación ha sido encontrar la relación que los descansos activos producen en el rendimiento académico sobre una muestra de 50 alumnos, dada la importancia que el ejercicio físico tiene en la sociedad actual, no solo por las mejoras que se producen a nivel cognitivo, sino por sus aportaciones a la salud de los más pequeños.

En primer lugar, es preciso mencionar que en este programa no solo se ha visto una mejora en las evaluaciones rea- 
lizadas a los sujetos para medir si han obtenido mejoras a nivel académico, sino que, como propone la Organización Mundial de la Salud (2010), también se han aumentado notoriamente los tiempos de actividad durante la realización de los descansos activos, que oscilaban entre los 10 minutos y 20 minutos.

Los resultados conseguidos sustentan la relación positiva entre la actividad física y la mejora en los logros académicos. En este sentido cabe destacar, que observamos estas mejoras en las evaluaciones pasadas de nuevo a ambos grupos después de trabajar los descansos activos, hallando un progreso más significativo en el grupo experimental que el grupo control. Autores como Ramírez, Vinaccia y Suárez (2004) han demostrado en sus estudios como el ejercicio físico tiene efectos positivos en diferentes factores, siendo el rendimiento escolar uno de ellos, donde se muestra una relación entre los logros académicos y las habilidades motoras por un mejor funcionamiento del cerebro, que en términos cognitivos se traduce en que se poseen unos niveles más altos de concentración, produciendo en el cuerpo una mejora en su comportamiento que incide de forma positiva en los procesos de aprendizaje.

Así mismo, en lo referente a los descansos activos los niños y niñas han desarrollado habilidades motrices básicas, han trabajado los prerrequisitos básicos de la lecto- escritura con conceptos como Arriba-Abajo, Dentro-fuera, Largo-corto o Grande-pequeño. Siempre contribuyendo al fomentado la AF en el aula, reduciendo las horas que permanecían sentados a lo largo de la jornada escolar. Estos resultados coinciden a los obtenidos en un estudio con 309 escolares chilenos, donde se observa que una hora de actividad física diaria está íntimamente relacionada con la mejora académica de los alumnos a los que el estudio fue sometido (Maureira et al., 2014). De este modo, en nuestro programa de intervención, se ha observado una mejora de los resultados académicos como pudimos ver en la asimilación de determinados contenidos curriculares y en la evaluación post-test después del desarrollo del proyecto.

En el desarrollo de programa de intervención se ha mostrado al igual que lo hace Roig (2013) en su trabajo, que el ejercicio produce una mejora notable en la salud cognitiva y en la optimización del rendimiento académico. De tal manera que mediante los descansos activos se ha podido ver la relación existente entre y la actividad física y la mejora en los resultados a nivel cognitivo.

Es importante destacar que a lo largo del desarrollo se han observado ciertas limitaciones. En primer lugar, no poder medir si la concentración y la atención de los alumnos ha mejorado después de la realización de los descansos activos y por otro, no haber trabajo con ningún instrumento que mida la actividad física, como podría ser un acelerómetro y ver la intensidad de las actividades, si era suficiente como para reducir el sedentarismo en el aula y su contribución a la disminución de la obesidad.

Para finalizar cabe decir que la actividad física practicada por niños, llevada a cabo de forma regular posee numerosos beneficios, habilidades motrices básicas como correr o saltar, son actitudes innatas al niño, sobre todo en edades tempranas, que son favorecedoras para la utilización de la energía cerebral. Es el papel de los educadores ocuparse de fomentar la actividad física y deportiva, para optimizar el rendimiento de los alumnos (Roig, 2013), y una forma clara de contribuir a ello es por medio de los descansos activos.

\section{Conclusiones}

Una vez realizado el programa de descansos activos en escolares, es posible concluir la efectividad del programa implementado, ayudando a la mejora de los niveles de rendimiento académico de los alumnos. De esta forma, con la utilización de este programa se contribuye a que los niveles de actividad física de los alumnos aumenten, favoreciendo un estilo de vida saludable, que no solo les ayude a su bienestar mental y cognitivo, si no que contribuya en otros campos como la salud, reduciendo posibles problemas de obesidad u otros problemas derivados de la inactividad física.

Igualmente, resulta necesario concebir como una práctica pedagógica específica, tal y como resalta el propio marco normativo, la presencia del docente de Educación Física para lograr alcanzar los deseados efectos propuestos desde la propia literatura científica, y el desarrollo competencial desde el marco curricular, lo que supone un reto para las administraciones educativas y la propia gestión de los centros educativos.

\section{Bibliografía}

1. Decreto $54 / 2014$, de 10 de julio, por el que se establece el currículo de la Educación Primaria en la Comunidad Autónoma de Castilla- La Mancha.

2. Decreto 67/2007 de 29-05-2007, por el que se establece y ordena el currículo del segundo ciclo de la Educación infantil en la Comunidad Autónoma de Castilla-La Mancha

3. Dunn, L.L., Dunn, L., y Arribas, D. (1997). Peabody. Test de vocabulario en imágenes. PPVT-III. Madrid: Tea Ediciones.

4. García, S. (2013). Situación actual de la psicomotricidad en la etapa de
Educación Infantil en España. [Consulta 18 de junio de 2018]. Recuperado de: http://reunir.unir.net/handle/123456789/1769

5. Herrador-Colmenero, M., Perez-Garcia, M., Ruiz, J. R., y Chillon, P. (2014). Assessing modes and frequency of commuting to school in youngsters: a systematic review. Pediatric Exercise Science, 26(3), 291-341.

6. Kahn, E. B., Ramsey, L. T., Brownson, R. C., Heath, G. W., Howze, E. H., Powell, K. E... Corso P. (2002). The effectiveness of interventions to increase physical activity. A systematic review. American Journal of Preventive Medicine, 22, 73-107. 
7. Kibbe, D. L., Hackett J., Hurley, M.; McFarland, A., Schubert, K. G. y Schultz, A. (2011). Ten Years of TAKE10!: Integrating physical activity with academic concepts in elementary school classrooms. Preventive Medicine, 52(Suppl 1), S43-S50. doi: 10.1016/j.ypmed.2011.01.025.

8. Martínez, J.; Aznar, S. y Contreras, O. (2015). El recreo escolar como oportunidad de espacio y tiempo saludable / The Recess School Space and Time as an Opportunity Healthy. Revista Internacional de Medicina y Ciencias de la Actividad Física y el Deporte, 15(59), 419-432. doi: 10.15366/rimcafd2015.59.002

9. Maureira, F., Díaz, I., Foos, P., Ibañez, C., Molina, D., Aravena, F.. Barra, M. (2014). Relación de la práctica de actividad física y el rendimiento académico en escolares de Santiago de Chile. Revista de Ciencias de la Actividad Fisica, 15(1), 43-50.

10. Ministerio de Sanidad, Igualdad y Servicios Sociales, Ministerio de Educación, Cultura y Deportes, Centro Nacional de Innovación e Investigación Educativa. (2014). ¡Dame 10 (Descansos Activos Mediante Ejercicio Físico). [Consultado 1 de junio de 2018].

11. Molina, J. y Martínez, V. (2014). La representación de la actividad física y los comportamientos sedentarios en las imágenes de libros de texto españoles del segundo ciclo de educación infantil. Reladei, 3(2), 175-200.

12. Organización Mundial para la Salud (2010). Recomendaciones mun- diales sobre actividad física para la salud. [Consultado 30 de mayo de 2018]. Recuperado de: http://apps.who.int/iris/bitstream/handle/10665/44441/9789243599977_spa.pdf;sequence=1

13. Ramírez, W., Vinaccia, S. y Suárez, G. R. (2004). El impacto de la actividad física y el deporte sobre la salud, la cognición y el rendimiento académico: una revisión teórica. Revista de estudios sociales, 18, 67-75.

14. Real Decreto 126/2014, de 28 de febrero, por el que se establece el currículo básico de la Educación Primaria.

15. Roig, M. (2013). Los efectos de la actividad física en el cerebro del niño. Hospital Sant Joan de Déu. Observatorio de salud infancia y adolescencia. [Consultado 8 de junio de 2018]. Recuperado de: http://www.infocop. es/pdf/Faros7Deporte.pdf

16. Sallis, J. F., Carlson, J. A., y Mignano, A. M. (2012). Promoting youth physical activity through physical education and after-school programs. Adolescent medicine: state of the art reviews, 23(3), 493-510.

17. Sánchez, M., Gutiérrez, D., Ruiz de la Hermosa, A., López, C. y Sánchez, M. I. (2017). Proyectos Escolares Saludables. Descansos activos. Guia para profesores: Ediciones de la Universidad de Castilla-La Mancha. [Consultado 5 de junio de 2018]. Recuperado de: https://ruidera.uclm. es/xmlui/bitstream/handle/10578/13451/Proyectos_escolares_saludables.pdf?sequence $=1$ 